\title{
Der Augenaufschlag
}

\section{Erhard Taverna}

Dr. med., Mitglied der Redaktion

«Die Natur schlägt im Menschen ihre Augen auf und bemerkt, dass sie da ist.» Wie romantisch hat sich das Wilhelm Schlegel (1775-1854) ausgedacht. Ein Primat mit Bewusstsein, mit einer vermutlich einmaligen Anordnung von Erleben, Zugang, Wachsein, Absicht, Aufmerksamkeit und Reflexion. Philosophen sprechen vom Erlebnischarakter des Bewusstseins oder vom phänomenalen Bewusstsein. Entscheidend bleibt die Innenperspektive oder Ich-Perspektive, die jedes bewusste Erleben mit sich bringt. Hat die Natur darauf gewartet, dass wir ihr unsere Entdeckung mitteilen? Können wir uns hineinfühlen in die Echowelt einer Fledermaus oder den magnetischen Orientierungssinn der Zugvögel?

Bildgebende Verfahren der Neurologie verorten immer genauer Sinneseindrücke, Gefühle und Stimmungen, sie verraten aber nichts über die individuelle Erlebnisqualität. Vieles deutet darauf hin, dass der Erlebnischarakter des Bewusstseins mehr ist als reine Informationsver-

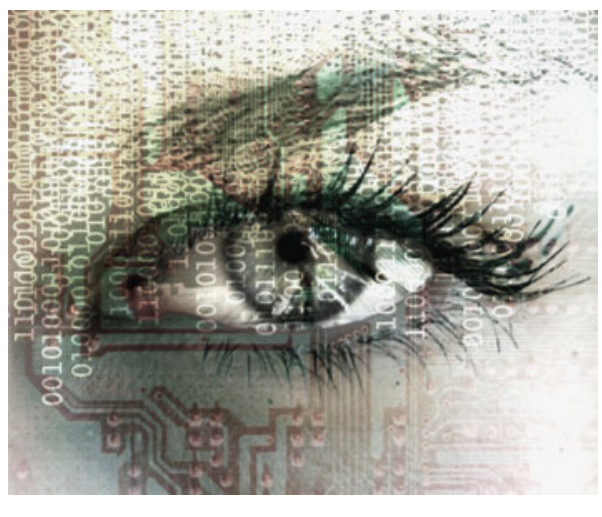

gesteuerter Abläufe, die wir fälschlicherweise unserem Bewusstsein gleichsetzen? Gross war die Anfangseuphorie des Blue-Brain-Projekts in Lausanne, eines Computermodells zur Simulation der Grosshirnrinde von Ratten. Kann man aus der Vernetzung neocorticaler Säulen auf die Persönlichkeit eines Menschen schliessen? Wenn David Chalmers mit seinen Überlegungen Recht hat, könnte jeder Mensch ein Zombie sein, da wir aus unserem eigenen Erleben nie mit restloser Sicherheit auf andere Menschen schliessen können. Die Erlebnisqualität von Wahrnehmungen bleibt eine Blackbox. In zehn Meditationen hat der amerikanische Philosoph George Steiner über Glanz und Elend des Denkens nachgedacht. Wir können scheinbar alles denken, werden aber niemals wissen, wie weit unser Denken die ganze Realität abbildet. Ein innerer Widerspruch, der Zweifel und Frustration erzeugt. Gemäss Steiner ein erster Grund für die fundamentale, unvermeidliche Traurigkeit, die gemäss Schelling im arbeitung. Auch wenn alle physiologischen Abläufe des Gehirns bekannt wären, liesse sich dieses phänomenale Bewusstsein naturwissenschaftlich nicht erklären. Könnten diese Prozesse nicht auch ohne dieses rätselhafte Bewusstsein ablaufen? Der australische Philosoph David Chalmers denkt sich in einem Gedankenexperiment einen philosophischen Zombie aus. Dieser kann äusserlich alles, was Menschen können, nur das Erlebnisbewusstsein fehlt ihm vollständig. Ein perfekter Automat, eine künstliche Intelligenz, wie sie die Begründer der KI-Forschung schon 1956 in Dartmouth an einem Workshop ausdachten. Kybernetischabstrakte Modelle einer mathematisch-logisch arbeitenden Maschine. Seither hat sich die Rechenleistung von Computern gemäss dem Moorschen Gesetz jährlich verdoppelt. Künstliche neuronale Netze dienen erfolgreich als Expertensysteme in der Medizin, und kürzlich haben Forscher mit einem Magnetresonanzscan gedachte Bilder, Symbole und Buchstaben visualisiert. Kommen wir mit Gedankenlesen der Definition von Bewusstsein näher, oder ist es nicht vielmehr unsere Interpretation immer komplexerer algorithmisch dunklen Grund des Bewusstseins wurzelt. Vielleicht steckt in allem Streben nach einer künstlichen Intelligenz ein säkularer Erlösungsgedanke. Maschinen als höheres Dasein kennen zumindest keine tiefsitzende Melancholie. Der polnische Denker Stanisław Lem hat mit seinem Roman "Solaris» in der Science-Fiction-Literatur eine Wegmarke gesetzt. Ein denkender Ozean auf einem fernen Planeten, mit dem Generationen von Wissenschaftlern vergeblich versuchen Kontakt aufzunehmen. Zu fremd, zu abartig bleibt ihnen diese anorganische Existenz. Dieser Ozean braucht keine Menschen, um zu bemerken, dass er da ist. Eine Metapher für unsere eigene Situation. Obwohl wir wissen, wie Fledermausorgane funktionieren, werden wir nie herausfinden, wie Fledermäuse aus der Innenschau die Welt erleben.

\section{Bildnachweis}

(c) Luis Manuel Tapia Bolivar | Dreamstime.com

\section{Literatur}

What is it Like to be a Bat, Thomas Nagel, Reclam 2016 George Steiner, Warum Denken traurig macht, Suhrkamp Verlag, erste Auflage 2008 - Stanisław Lem, Solaris, Ullstein, 8. Auflage 2014 